\title{
sciendo THE USE OF A MATHEMATICAL MODEL OF MARINE DIESEL ENGINE IN A COMPUTER PROGRAM
}

DOI 10.2478/ntpe-2018-0056

\author{
mgr inż. Artur Bogdanowicz \\ dr hab. inż. Tomasz Kniaziewicz \\ dr inż. Marcin Zacharewicz \\ Polish Naval Academy, Poland
}

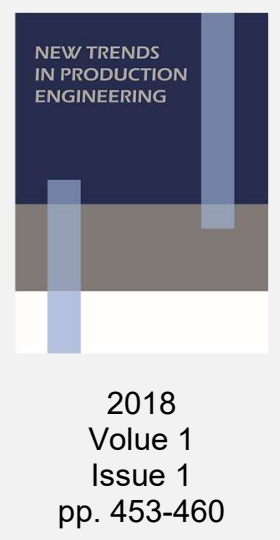

\begin{abstract}
The paper describes the application of the author's mathematical model of gas-dynamic processes for a marine piston engine based on a computer program. The developed mathematical and numerical model is designed to conduct simulation diagnostics. Therefore, it is possible to carry out calculations for motors in different technical conditions and observing influence of changes in technical condition on selected parameters of its work. Simulation of changes in technical condition is carried out by modifying parameters of structure's model object. The article contains a detailed description of each options of the computer program. From the main program window, user can select type of engine model (supercharging method, cylinder number, work order, stroke and piston diameter and a number of other parameters). Through a window of simulation of known and recognizable damages such as: change in fuel dose for each cylinder, change in intake and outlet valves, leakage of piston-ring-cylinder system, change of injector hole cross section. Final windows show results of calculations in form of mileage parameters of engine as a function of crank angle.
\end{abstract}

Keywords: engine model, computer program, engine technical state simulation

\section{INTRODUCTION}

The early conception of research has been resulted the searching assessment of technical condition of auxiliary diesel engines which was not equipped with indicator valves (Cwalina and Zacharewicz 2011, Zacharewicz 2012).

The mathematical model is a set of balance equations describing in a simplified way the processes and physical phenomena taking place in a modeled real object. Most models refer to dynamic processes whose mathematical description contains differential equations. Their solution is to carry out multiple calculations taking into account a small increment of time (iteration). This kind of calculations require very high precision (range of variables). All this causes that mathematical models are implemented in programming languages and solved with the use of computers. The rapid increase in computer performance allows to make more calculations in less time with ever more precision. Use of computers allow to minimize a number of simplifying assumptions thus increasing an adequacy of models in relation to modeled processes. In addition to the undoubted advantages of solving equations by using computers it can sometimes lead to errors result from limited range of variables used (socalled quantization error) and apply a quasi-stationary approach to dynamic issues.

One of the issues of authors was creation of physical process models occurring in piston internal combustion engines for diagnostic purposes. For this purpose, a physical model of a marine engine (Cwalina and Zacharewicz 2013, Bogdanowicz, Kniaziewicz and Zacharewicz 2017) has been developed and a mathematical model based on it (Cwalina, Kniaziewicz, Rudnicki, Zacharewicz 2013, Cwalina and Zacharewicz 2015, Kniaziewicz and Zacharewicz 2016, Kniaziewicz and Zacharewicz 2017). These models form a basis for development of a computer program in a high level programming language. 


\section{THE PROGRAM}

According to the research methodology, an algorithm has been developed containing the stages of research (Figure 1).

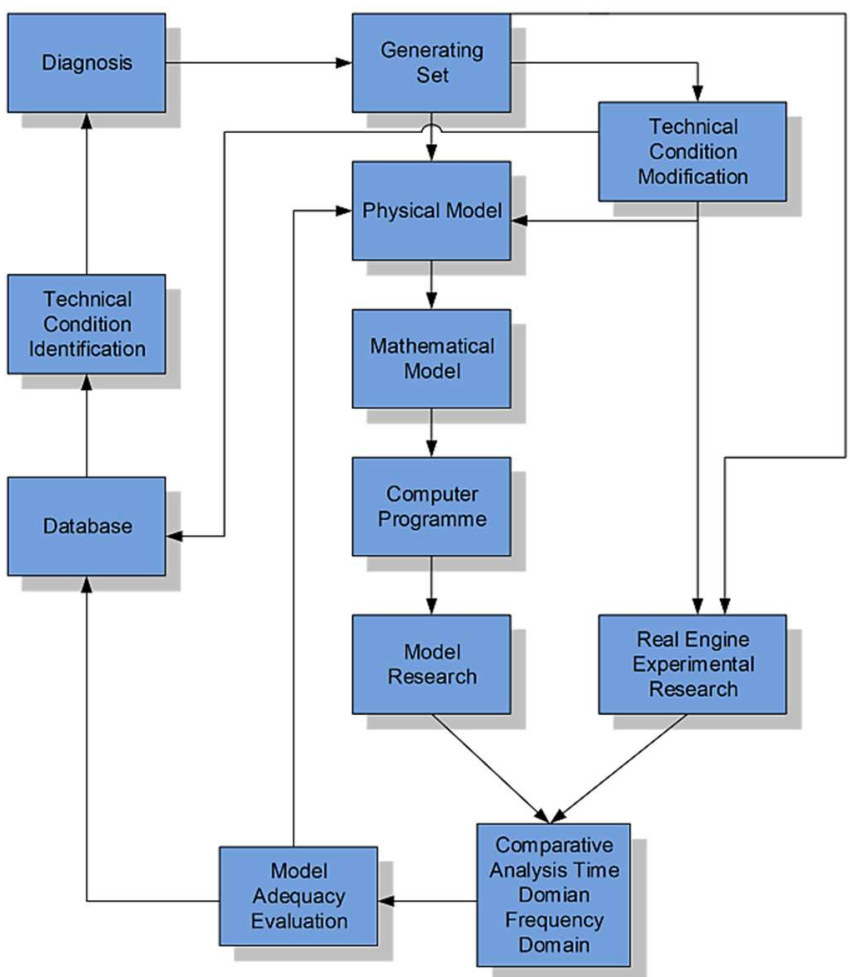

Fig. 1. Diagram of research implementation.

Source: (Korczewski and Zacharewicz 2012, Kniaziewicz and Zacharewicz 2017)

In accordance to the algorithm, the research object is diesel - electric generator, which is a part of the ship power plant. Based on this, the physical model of processes in a marine engine has been developed, taking into account both the thermodynamic and the kinematic processes occurring in a marine engine (Cwalina and Zacharewicz 2013). Based on the physical model, a mathematical model of these processes has been developed (Kniaziewicz \& Zacharewicz 2016).

The developed computer program is based on equations of a mathematical model of a marine piston engine (Kniaziewicz \& Zacharewicz 2016). It has been written using the RAD Studio object-oriented programming language XE5. In the model takes into account a gas dynamics processes occurring in an engine cylinders and dynamics of a piston-crank system has been mapped. The program takes into account a possibility of modifying practically all construction parameters having significant (from the authors' point of view) influence on the performance of a piston engine. This approach allows to easily modify a input data to the model. It makes that it could to be virtually modeled any marine piston engine.

The engine parameters that can be modified are:

- crankshaft rotation speed,

- engine boost pressure,

- value of excess air ratio or engine power (these parameters are closely related);

- chemical composition of fuel, values of thermal conductivity coefficients for: cylinder liners, piston head, head,

- fuel temperature, cooling water, supply air,

- values of exhaust gas flow resistance.

Other variable parameters are geometrical dimensions of individual components of the motor structure:

- number and layout of engine cylinders, 
- number of inlet and outlet valves,

- combustion chamber height or compression value,

- dimensions of a crankshaft system such as cylinder diameter, connecting rod length, crankshaft crank arm length or piston stroke,

- cam-valve-valve seat geometry,

- opening and closing angles of inlet and outlet valves,

- thickness of a cylinder liner,

- thickness of a piston crown,

- head thickness,

- injection advance angle,

- number and cross-sectional area of the injector holes,

- masses of piston and crank components.

A quasi-stationary approach to dynamically changing phenomena was applied in the mathematical model (Cwalina \& Zacharewicz 2013). This means that all parameters of the working medium are treated as constants in short time periods. Parameters only change in iterations corresponding to time increment or crankshaft rotation angle. All equations of the mathematical model are solved with a resolution of 0.1 degrees of crankshaft rotation. Which results in the calculation of 7200 states for each cycle. In addition, due to the need to accept some initial conditions of the model, a first duty cycle is discarded. This procedure is introduced because of each cylinder at the start of the calculation is in a different phase of the duty cycle. This means that some processes may not be included in the first work cycle, what is more erroneous values of certain engine parameters such as cylinder mass, temperature and pressure can be assumed. These parameters get the right values after a full duty cycle including cylinder replacement, fuel injection, etc.

The main program window is shown in Figure 2.

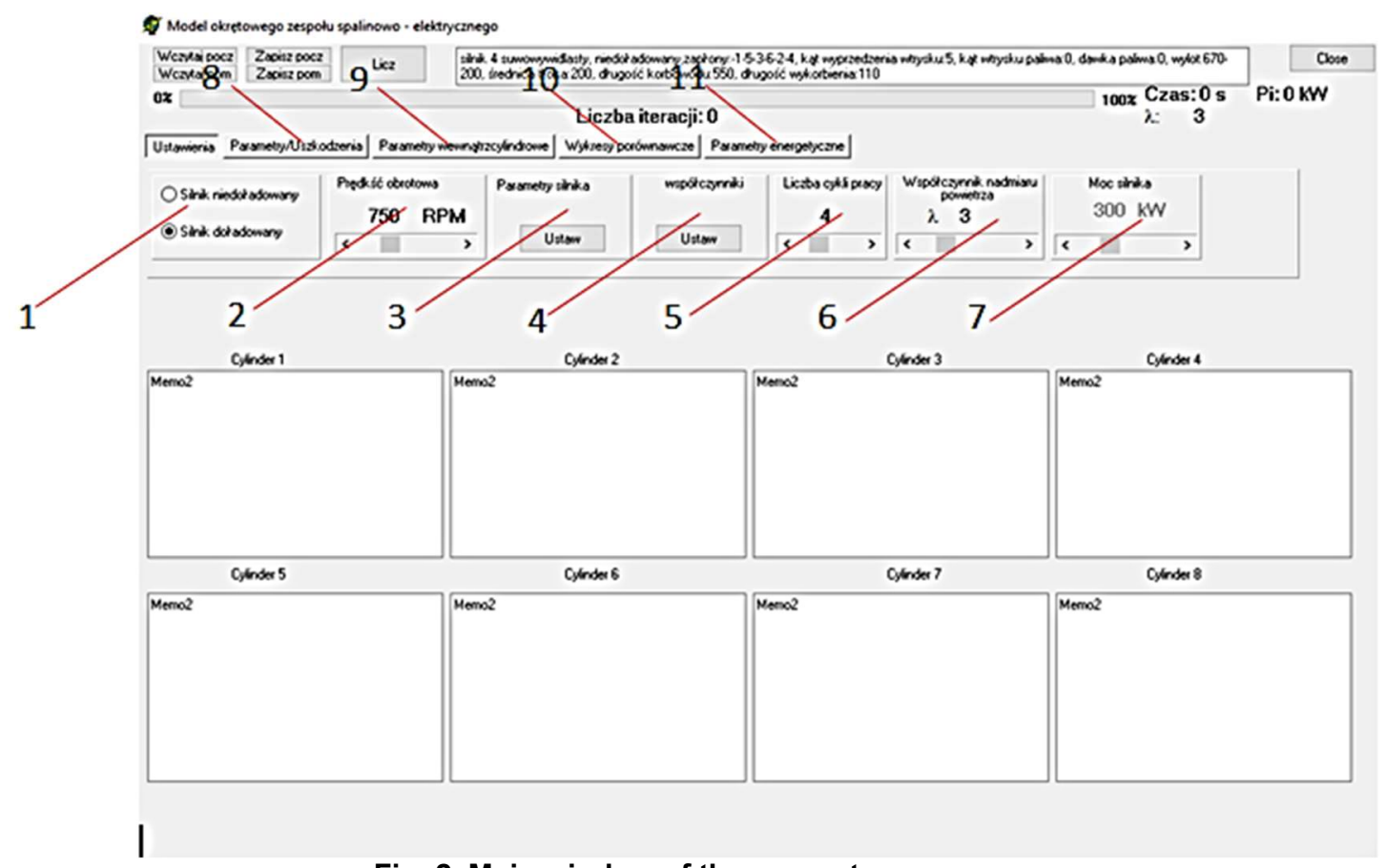

Source: own elaboration

Fig. 2. Main window of the computer program.

From the main window of the computer program you can choose how to supply the engine with air, ie whether the engine is charged or not (Fig. 2 -1). You can specify for which rotational speed need to calculate (Fig. $2-2$ ). It is also possible to open the "parametry silnika" tab, where you can set basic parameters of an engine such as its geometry, fuel chemical composition, boost pressure, etc. (Fig. $2-3$ ). The next tab allows you to modify the 
flow rate for exhaust, air and fuel (Fig. 2 - 4). Another parameter that can be modified from the main program window is a number of engine cycles taken into account during modeling (Fig. 2 $-5)$. It is also possible to make calculations for a determined value of a excess air coefficient $\lambda$ (Fig. $2-6$ ) or for a set motor power (Fig. $2-7$ ). Both parameters influence on amount of fuel delivered to engine cylinders. Calculations are performed repeatedly and each time excess air ratio (fuel dose) is changed. The procedure is performed until an assumed motor power is reached.From the main window you can initiate calculations using the "Licz" button and save and load the results of the calculations. The main window of the program allows access to a tab where simulations parameters can be made (Fig. $2-8$ ). This option is shown in Figure 3. It is also possible to access graphs describing engine performance in the form of a parameter plot as a function of a crankshaft rotation angle (Fig. 2 - 9). Another option for presenting modeling results is the „Wykresy porównawcze” panel (Fig. 2 - 10). It allows you to display up to six overlapping graphs of engine performance parameters as a function of a crankshaft rotation angle. This is particularly useful when analyzing an effect of a damage on waveforms. When you select „Parametry silnika” (Fig. 2 -3), the window shown in Figure 3 will open.

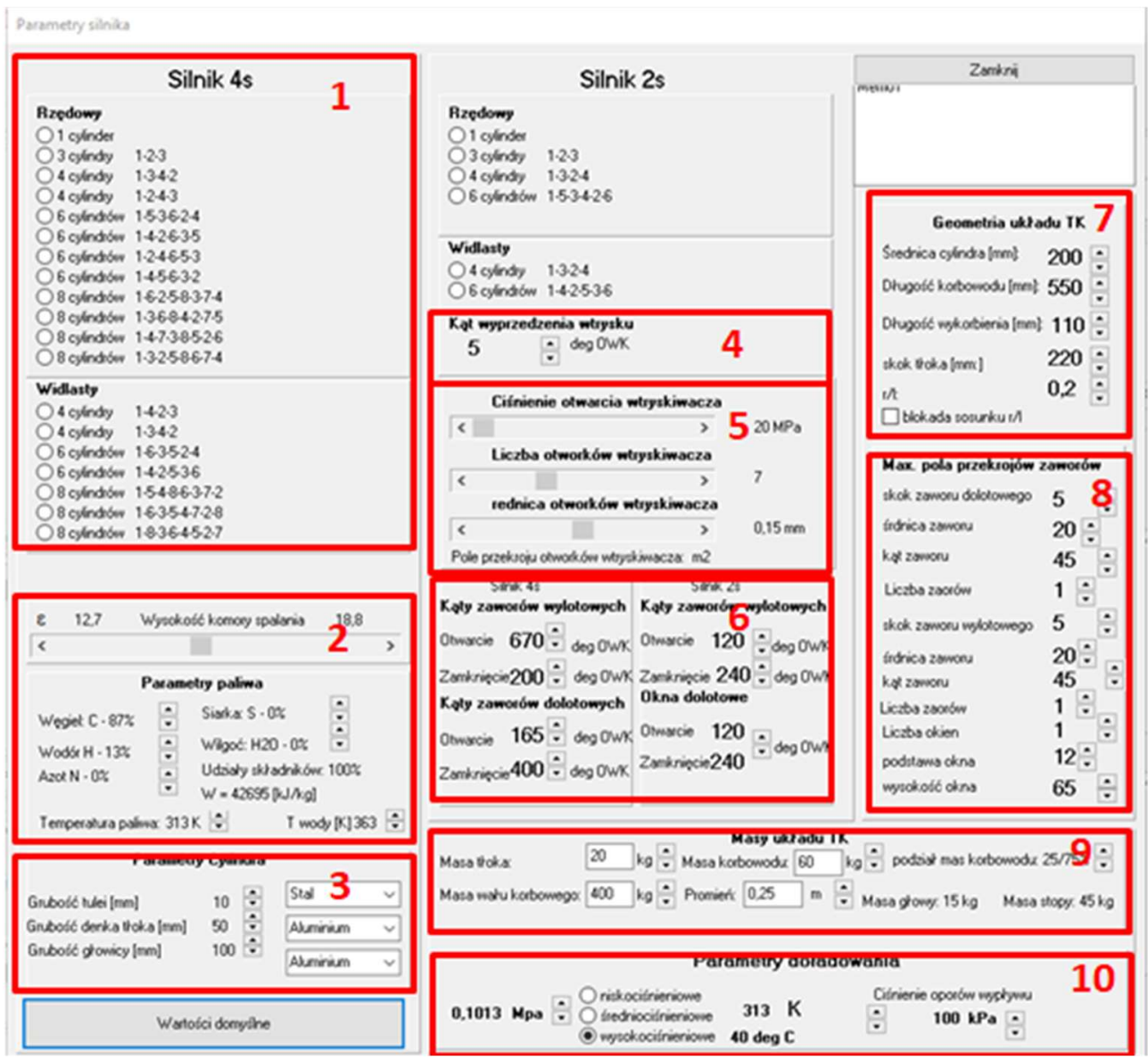

Fig. 3. Window of the operating parameters of the piston engine combustion engine.

Source: own elaboration

From this level you can set all relevant engine parameters from the model's point of view. The figure "1" indicates selection of a cylinder system of internal combustion engine. You can choose a number and layout of cylinders. Additionally, it is possible to choose the order of work of individual cylinders. It is possible to model engines in the row and fork cylinders. By choosing the layout and a number of cylinders, you also choose the order of their work. Another separate panel (Fig. $3-2$ ) available in „Parametry paliwa” window is choice of combustion chamber height and compression ratio. In this panel you can also modify chemical composition of a fuel, which changes its calorific value. Changing chemical composition also changes parameters of the intra-cylinder factor (change in individual value of gas constant, 
which also depends on instantaneous value of an excess air ratio). Another panel (Fig. $3-3$ ) allows for modification of heat exchange parameters between a medium inside a cylinder and cooling water, air and oil. Panel 4 allows you to modify your overtaking angle of injection. Panel 5 can be usedto change parameters of injection molding factors such as injector opening pressure, number of injector holes and cross section area of injectors. Panel 7 is designed to modify geometric parameters of piston-cylinder system. Allows you to modify the crankshaft crankcase length, connecting rod length, and cylinder diameter. Panel 8 allows you to select operating parameters of intake and exhaust valves. Allows you to specify the number of inlet and outlet valves, their diameters, maximum valve lift and valves characteristic angles. The panel titled "Masy układu TK" allows you to modify the masses of all elements that make rotational movement, reciprocating and mixed. The panel (Fig. 3 - 10) you can set engine boost parameters such as boost pressure, charge air temperature and resistance in the exhaust gas duct. The program uses the „Parametry domyślne” button, which sets all engine performance parameters according to SULZER 6AL 20/24 laboratory engine installed in AMW engine laboratory. This allows the model to be verified on the basis of comparing the modeling results with the results of the measurements made on the real object. At this stage the program has been able to simulate a four-stroke engine however, the possibility of extending the model and program with two-stroke engines has been taken into account.

Selecting „Parametry/uszkodzenia” (Fig. $2-8$ ) in the main window opens a tab shown in Figure 4. They show basic parameters of engine, such as an order of operation of individual cylinders, values of the DMP angles, and opening/closing angles of valves. Field 2 shows modifications of engine operating parameters simulating a selected faults. Using the "switches" shown in box 3 , you can select a variant in which the program works, it means that user can modeling efficient engine or with faults. If you modify any of parameters in panel 4, the program automatically switches to simulated state. You can select an accuracy of a calculation in a field marked with "3". Increasing accuracy results in a drastic increase in the measurement time. When determining the impact of engine damage on the timing of selected parameters of its work, the influence of the engine speed regulator on the fuel doses delivered to the engine cylinders is taken into account.

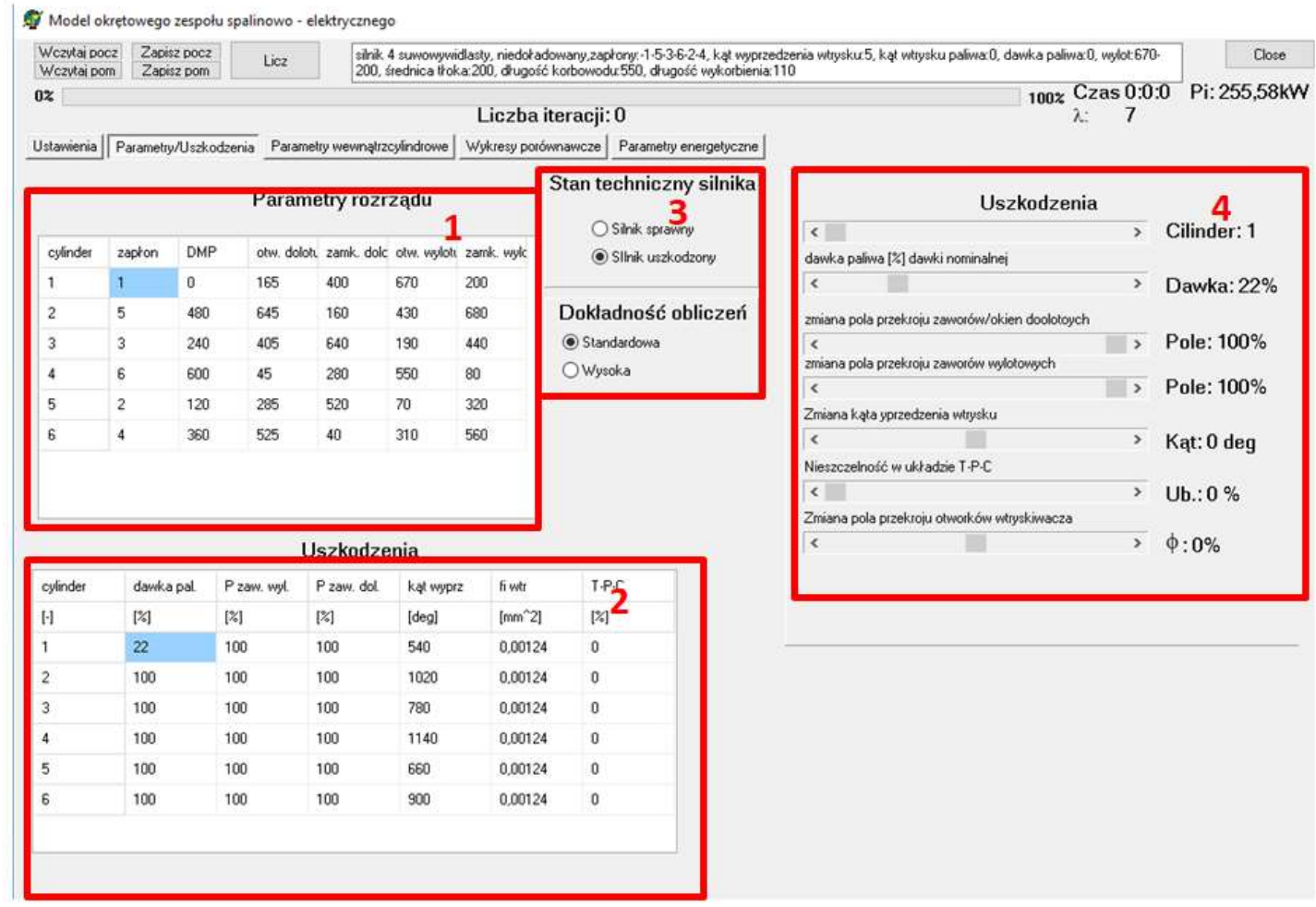

Source: own elaboration

Fig. 4. View table "Parametry/uszkodzenia". 
In case of determining influence of engine damage on timing of selected operating parameters takes into account an influence of the engine's governor on fuel doses delivered to engine cylinders. This is done in such a way that a condition of equal engine's indicated power (efficient and damaged engine) is to be fulfilled. To achieve this, an operating cycle of engine is modeled repeatedly by changing the value of an excess air ratio (amount of fuel) to fulfill this condition. The „Parametry/uszkodzenia” tab is shown in Figure 4.

The „Parametry wewnątrzcylindrowe” tab shown in Figure 5 allows you to visualize the waveforms of an engine performance measured as a function of a crankshaft rotation angle. There are four fields in this tab: the first field allows you to select a number of cylinders and parameters which will be displayed in box 4 . Field two allows you to show in one graph waveforms of two engine parameters or the same parameter for two different simulations e.g. for two technical states of an engine. This allows you to assess an impact of damage on observed parameters. Table 2 allows you to scale each of waveforms shown, and also allows you to move these graphs vertically. Table 3 allows you to select a parameter presented in a form of waveforms in Table 4. These parameters are: parameters of a piston movement, parameters of timing system, gas dynamic parameters in an engine cylinder, parameters of flow through the valves.
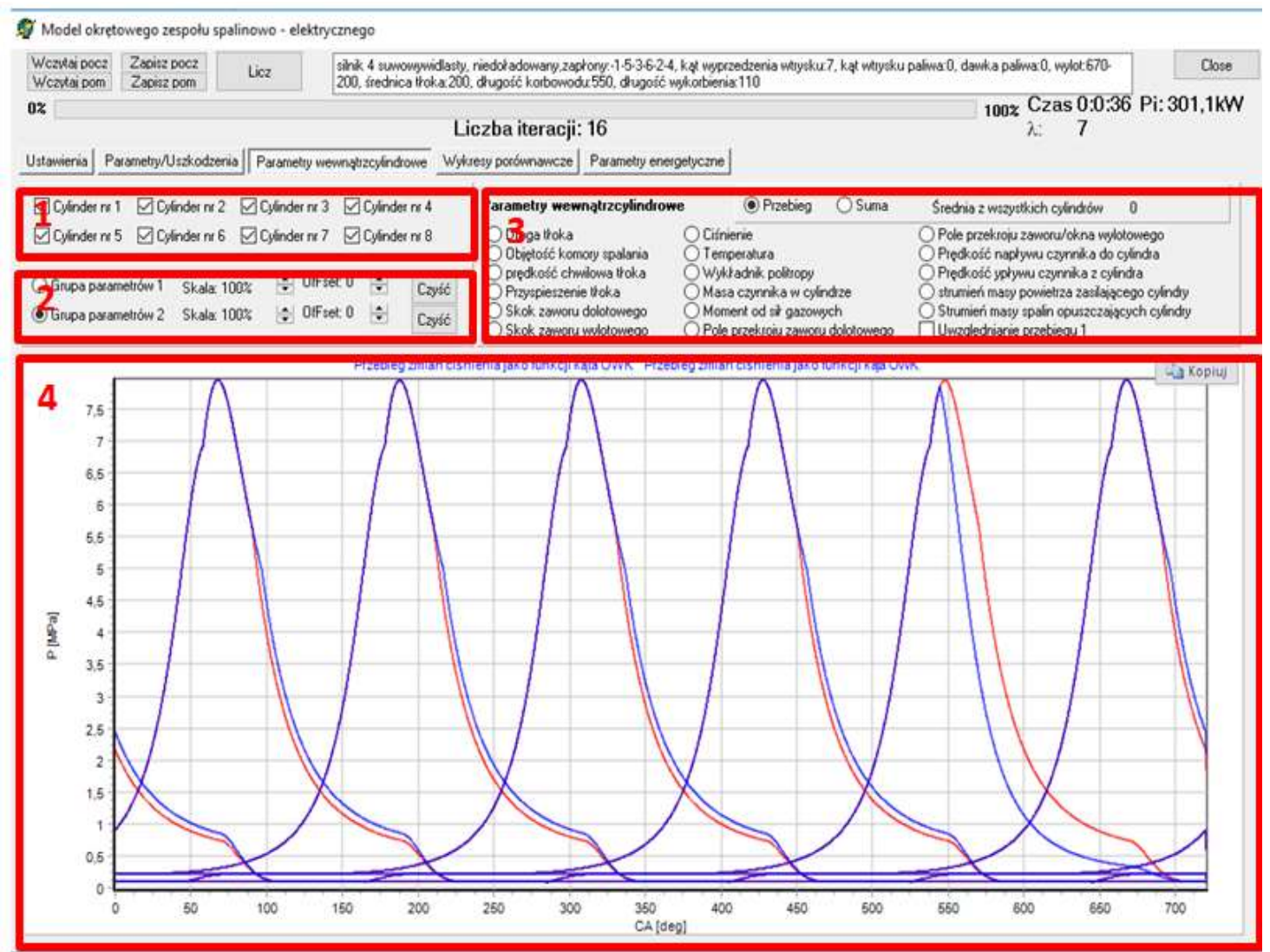

Fig. 5. View of the tab „Parametry wewnątrzcylindrowe”.

Source: own elaboration

Figure 6 shows the „Wykresy porównawcze” tab, which is intended to show the performance of individual cylinders as a function of a crankshaft rotation angle. It allows a presentation of engine parameters (the same parameters as in the tab "Parametry wewnątrzcylindrowe" box 3 . In this tab there is a possibility to select a cylinder for which specified parameters will be presented. Additionally, it is possible to present test results for up to 6 simulations (e.g. for different engine technical conditions). 


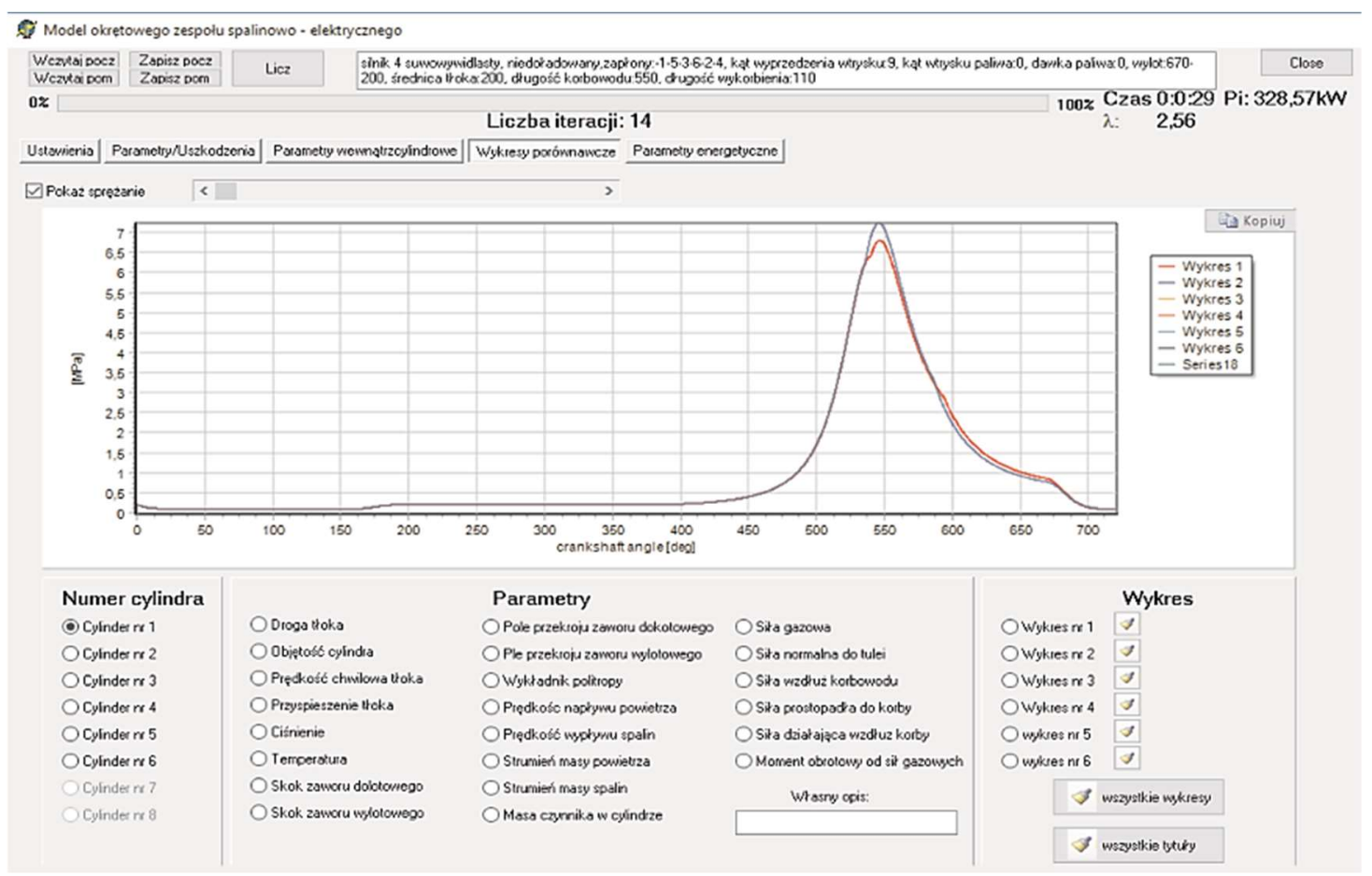

Source: own elaboration

Fig. 6. View of the tab „, Wykresy porównawcze”.

\section{CONCLUSION}

The computer program presented in this article is based on equations of mathematical model. At the present stage of its development, there have been implemented equations describing processes and phenomena inside cylinders that take place during a working cycle. The process of filling cylinders with air, the process of compression, injection and combustion of the fuel/air mixture has been taken into account. The process of expansion and outlet of exhaust gases has also been taken into consideration. In addition, the process of heat transfer between a cylinder and its walls has been taken into consideration during an entire engine work process. The presented computer program (mathematical model) allows to simulate a series of engine failures. This is accomplished by modifying operating parameters of any engine cylinder. Modification involves changing a geometry of its components and changing the amount of fuel injected into the cylinders. At this stage, work is underway on modeling the influence of a technical condition of an engine on a fluctuation of its angular velocity (taking into account dynamics of a crankshaft system and rotating masses). In addition, the process of developing a mathematical model and computer program is accompanied by real-world measurements that will allow for the assessment of its adequacy. The adequacy assessment is performed on SULZER engines type 6AL 20/24 and Leyland type 6SW400, which are part of the Naval Academy's laboratory base.

\section{REFERENCES}

Cwalina A. Zacharewicz M. (2011), The conception of diagnosis in auxiliary diesel engine at limited monitoring susceptibility in automated ship power plant, Polish Journal of Environmental Studies Vol. 20 No. 5A, 2011, pp. 46-51.

Korczewski Z., Zacharewicz M. (2012), Alternative diagnostic method applied on marine diesel engines having limited monitoring susceptility, Transaction of the Institute of Measurement and Control, Vol. 34, No. 8, 2012, pp. 937-946.

Zacharewicz M. (2012), An analysis of the assessment of the technical condition of a marine diesel-electric set based on the exhaust gas pressure and other energy parameters measurements, Journal of POLISH CIMAC Vol7 No.2, 2012, pp. 255-264.

Cwalina A., Zacharewicz M. (2013), Research on energetic processes in a marine diesel engine driving a synchronous generator for diagnostic purposes PART 1 - Physical model of the processes, Journal of POLISH CIMAC Vol8 No.1, pp. 97-104. 
Cwalina A., Kniaziewicz T. Rudnicki J. Zacharewicz M. (2013), Technical evaluation of marine auxiliary diesel engine on the basis of parameters synchronous generator., Combustion Engines 3/2013 (154), 2013.

Cwalina A, Zacharewicz M.(2015), Problems of mathematical modeling of the marine diesel engine working cycle for the diagnostic purposes. Solid State Phenomena, Vol. 236, 2015, pp. 212-219.

Kniaziewicz T., Zacharewicz M. (2016), Research on energetic processes in a marine diesel engine driving a synchronous generator for diagnostic purposes PART 2 - Mathematical model of the processes, Journal of Polish CIMEEAC 2016 Vol. 11 No 1 pp. 199-209.

Bogdanowicz A., Kniaziewicz T. Zacharewicz M. (2017) ,Physical model of energetic processes in the marine diesel engine, Scientific Journal of Polish Naval Academy 2(211), 2017, pp. 5-12

Kniaziewicz T., Zacharewicz M. (2017), Mathematical modelling malfunctions of marine diesel engine, MATEC Web of Conferences 118,00001.

Kniaziewicz T., Zacharewicz M. (2017), Modeling of the operating process in a marine diesel engine, Journal of Marine Engineering \& Technology. Vol. 16, 2017 pp. 1-7.

Date of submission of the article to the Editor: 06/2018

Date of acceptance of the article by the Editor: 09/2018 